\title{
OS DIREITOS SEXUAIS E O ENFRENTAMENTO DA VIOLENCIA SEXUAL ${ }^{\text {I }}$
}

\author{
Pedro Paulo Gastalho de Bicalho* \\ Janaina Rodrigues Geraldini** \\ Kely Cristina Magalhães*** \\ Luan Carpes Barros Cassal****
}

\section{Resumo}

O artigo tem como temática a problematização acerca da emergência dos direitos sexuais como direitos humanos e dos processos de criminalização contemporâneos que se materializam na violência sexual, colocando em análise suas múltiplas formas de entendimento e delimitaçóes. Busca-se visibilizar produçóes de saberes - sempre articulados a relaçóes de poder - para pôr em questão processos de subjetivação, a partir da análise do funcionamento do poder biopolítico e seus efeitos na contemporaneidade.

Palavras-chave: direitos humanos; direitos sexuais; violência sexual; biopolítica.

\section{Abstract}

SEXUAL RIGHTS AND SEXUAL VIOLENCE CONFRONTATION

The theme of this article is the questioning about the emergence of sexual rights as human rights and criminalization processes that are manifest in contemporary sexual violence, putting in its multiple forms of analysis and understanding boundaries. The aim is to visualize production of knowledge - always articulated power relations - for questioning processes of subjectivity from the analysis of the biopolitical power operation and its effects on contemporary society.

Keywords: human rights; sexual rights; sexual violence; biopolitics.

* Instituto de Psicologia, Universidade Federal do Rio de Janeiro, UFRJ, Rio de Janeiro, RJ, Brasil. Conselho Federal de Psicologia, Brasília, Distrito Federal, Brasil. E-mail: ppbicalho@ufrj.br.

** Instituto de Psicologia, Universidade Federal do Rio de Janeiro, UFRJ, Rio de Janeiro, RJ, Brasil. E.mail: jgeraldinipsi@yahoo.com.br.

*** Instituto de Psicologia, Universidade Federal do Rio de Janeiro, UFRJ, Rio de Janeiro, RJ, Brasil. E.mail: kelyzinharj@hotmail.com.

**** Instituto de Psicologia, Universidade Federal do Rio de Janeiro, UFRJ, Rio de Janeiro, RJ, Brasil. E-mail: luancassal@yahoo.com.br. 


\section{Introdução}

Ao colocarmos em análise os mecanismos históricos que fazem funcionar determinados modos de articular o poder no Ocidente, damos destaque - aqui - aos séculos XVIII e XIX e ao que é caracterizado como o nascimento da biopolítica.

Michel Foucault (1988) discorre sobre a "biopolítica" como uma série de tecnologias de poder para governo e controle da vida das populaçóes, e neste regime a morte é assegurada pelo então denominado racismo de Estado. A eliminação daqueles considerados "diferentes" não é pautada pelo ódio, mas pelo argumento do fortalecimento biológico da espécie. A biopolítica se aplica através das normas e, para sujeitos e grupos que transgridem, cabem punições. A sexualidade como conhecemos e suas normas operam como um potente dispositivo de controle de corpos, populaçóes e modos de existência por produzir uma interface entre corpos individualizados e a reprodução da espécie. São necessários contornos bem definidos àquilo que é criminalizado, se apoiando na hegemônica política identitária, que nos ilude que os contornos subjetivos são definitivos, essenciais, imutáveis. $\mathrm{E}$ a sexualidade, ao ser tomada como referência de funcionamento biopolítico, tem nas relaçóes de gênero seu paradigma de construção.

\section{Gênero e sexualidade como "categorias de sequestro"}

Gênero e sexualidade, ao serem tomados como essências reveladoras do humano, tornaram-se dispositivos de controle dos corpos, das populaçóes e dos modos de existência. Um dos efeitos disso, nos diz Foucault (1988), é quando a identidade é tomada como regra ética universal, tornando-se o problema mais importante da existência, regendo relaçôes em que as normas sexuais e de gênero são fundamentais na construção das tecnologias de poder na nossa sociedade - e os desviantes são produzidos pela mesma estratégia que os pune.

Foucault (2003) assinala o momento do internamento nas instituições de sequestro como um acontecimento indispensável à formaçáo de uma rede de vigilância, controle e correção que isola o tempo, o corpo, o saber e a vida das pessoas, tornando imprescindível a figura do especialista. Mas Foucault também nos lembra do poder que se exerce sobre a vida (aqui, "em liberdade"), controlada a céu aberto e vigiada nas entrelinhas do poder. O olhar está voltado para o indivíduo e suas virtualidades, para o seu suposto grau de periculosidade, reproduzindo-se dispositivos de captura e de controle. 
A sexualidade - atravessada por discussóes de gênero - surge, então, como critério de subjetivação. Deste modo, instituem-se sexualidades normais e anormais e estas, como categorias médico-psiquiátricas, são categorizadas e "tratadas". Abre-se espaço para a tentativa de "recuperação" da sexualidade através de técnicas médicas, psicoterápicas ou mesmo pelo genocídio destas populaçóes. Para elaboração e manutenção deste dispositivo, são convocados as ciências, os pesquisadores e os especialistas. Toma força não só a psiquiatria, mas saberes que respondem sobre o humano, dos quais damos destaque aqui à Psicologia. Limitam-se, assim, os direitos sexuais - afirmando que tais direitos correspondem a "determinadas" sexualidades -, ao mesmo tempo que a violência sexual é reduzida a um formato de transgressão, cujos "transgressores habituais" correspondem, não por acaso, a "determinados perfis".

Ao longo do século XIX, o positivismo europeu ganha projeção em larga escala e influencia diretamente a cultura ocidental. Despontam as teorias criminológicas que, articuladas a saberes como Psicologia, Antropologia e Estatística, são apoiadas em uma natureza humana, numa dita essência criminosa. Cientistas como Lombroso, precursor da Antropologia Criminal, ou Ferri, defensor da ideia de que o crime possuía causas socioambientais, eram as referências da época (Rauter, 2003). Juntamente com outros teóricos, defensores do determinismo biológico apresentam suas contribuiçóes para o criminoso tornar-se objeto de seu crime e, dessa forma, tornar a pena uma espécie de instrumento de punição e correção - além de defender a sociedade dos entendidos como "degenerados".

A privação de liberdade passa a se apoiar em arcabouço técnico e teórico que torna possível, mesmo que idealmente, a ideia de transformação dos sujeitos dos desvios. $\mathrm{O}$ aparelho carcerário constrói três esquemas, como demonstra Foucault: "A cela, a oficina e o hospital. A margem pela qual a prisão excede a detenção é preenchida de fato por técnicas de tipo disciplinar" (Foucault, 2003, p. 208). E, no âmago das novas tecnologias de "vigiar e punir", determinados saberes se tornam fundamentais: Criminologia, Psicologia, Psiquiatria, Pedagogia, Sociologia, Assistência Social, Estatística. Não é acidentalmente que esses saberes utilizam como ferramenta principal o Exame, seja através de laudos e entrevistas, seja através de pareceres e avaliaçóes. Nesses instrumentos o poder está na palavra do especialista que diz quem é normal ou anormal, delimita os perigosos e quem deve ficar detido em uma instituição prisional, que cabem aqui celas de segurança máxima ou desejos trancados em "armários". Pois o corpo do sujeito sexual também é alvo de intervençôes "científicas" com objetivo de prever, controlar e corrigir a sexualidade desviante (Fry \& Macrae, 1993). Deste modo, a todo o momento os técnicos da correção são convocados a decidir sobre a vida alheia, instituindo e reproduzindo práticas normatizadoras, coercitivas e despotencializadoras (Rossotti \& Campos, 2010). 
A prisão não é apenas o espaço desenhado para punir e corrigir, não é apenas o lugar de execução da pena, mas sim um local de observação dos indivíduos que ali se encontram. E o objetivo dos que observam não é apenas vigiar e sim conhecer e identificar os comportamentos dos "perigosos", estabelecendo prevençôes e destacando progressivas "melhoras". A instituição-prisão (e não somente o "estabelecimento-prisão") se torna, então, lugar de formação de saber sobre os "prisioneiros" e neste lugar a figura do especialista "psi” se tornou imprescindível. Prisão, aqui, entendida não somente por uma "anatomia" caracterizada por sua estrutura, mas por uma "fisiologia" que diz respeito a funçóes. "Função-prisão", portanto, como um conceito que transcende as detençóes que hoje compóem os sistemas estaduais (e federal) de administração penitenciária. Em que outras prisōes utilizamos do saber-poder científico para a produção e manutenção de certos “jogos de produção de verdade”, como ferramentas de produzir máquinas políticas de controle?

No campo jurídico-formal "todos são iguais perante a lei, sem distinção de qualquer natureza [...]. Homens e mulheres são iguais em direitos e obrigaçôes, nos termos da Constituição" (Art. 5º, caput e inciso II da Constituição Federal). A construção do masculino e do feminino em uma sociedade, no entanto, varia de acordo não somente com seu conjunto de normas instituídas, mas principalmente por tradiçóes, valores e subjetividades, materializadas pela existência de indicadores que traduzem as desigualdades vivenciadas pela populaçâo, apesar dos pactos, tratados e resoluçóes construídas na direção da promoção de igualdade.

\section{Direitos sexuais são também direitos humanos}

Direitos humanos, em sua proposição universal, são datados da Declaração Universal de 1948 e afirmados no Pacto sobre direitos civis e políticos e no Pacto sobre direitos sociais, econômicos e culturais, consolidados na II Conferência Internacional de Direitos Humanos de Viena em 1993.

Foram diversas as conferências da ONU que trabalharam a questão de gênero a partir das discussóes de direitos humanos, afirmando os direitos sexuais e reprodutivos como direitos humanos. Podemos citar a Conferência Internacional sobre as mulheres, em Nairobi no ano de 1975, a Conferência sobre População, em 1995 no Cairo, a Segunda Conferência Internacional sobre as Mulheres (Beijin, 1996) e a Conferência de Dublin, em 2000, sobre a questão racial étnica como direitos humanos. Em todas as citadas o Brasil foi signatário. A pergunta que fica é: onde estão as políticas públicas decorrentes de tais tratados? 
Para Michel Foucault (1979), a produção de verdades é sempre transitória, política e associada aos seus efeitos. Não há uma verdade última, um ponto de origem a ser desvendado ou uma finalidade na história, mas a construção tática de relaçóes de poder. Neste sentido, o que entendemos hoje como violência é efeito de relaçóes entre exercícios de poderes e produção de saberes sobre o humano.

Entendemos aqui a violência como um dispositivo - um espaço de permanente reconstrução - em que se encontram linhas de discursos, de práticas e de subjetivação. O dispositivo, para Foucault, significa:

[...] um conjunto decididamente heterogêneo que engloba discursos, instituiçôes, organizaçôes arquitetônicas, decisōes regulamentares, leis, medidas administrativas, enunciados científicos, proposiçôes filosóficas, morais, filantrópicas. Em suma, o dito e o não dito são os elementos do dispositivo. O dispositivo é a rede que se pode estabelecer entre esses elementos (Foucault, 1979, p. 244).

Os dispositivos operam na invenção e conexão com outros dispositivos. Assim, tomar a violência como um dispositivo revela uma série de relaçóes de poder. O poder, em seu aspecto tático, funciona em uma rede, um emaranhado em que as construçóes e disputas se atravessam e se afetam. As tensōes a respeito do que é ou não aceitável como violência dão visibilidade a linhas de força, processos de produção de subjetividade.

Foucault (2001) apresenta as três figuras que constituem o terreno do discurso sobre o "anormal": o monstro humano, o indivíduo a ser corrigido e a criança masturbadora. $\mathrm{O}$ monstro humano, deste modo, é aquele que constitui "em sua existência mesma e em sua forma, não apenas uma violação das leis da sociedade, mas uma violaçáo das leis da natureza" (Foucault, 2001, p. 69). Ele combina o impossível com o proibido e, mesmo sendo o princípio de inteligibilidade de todas as formas da anomalia, o monstro é, em si, ininteligível ou dotado de uma inteligibilidade tautológica. Neste contexto, o anormal é, no fundo, um monstro cotidiano, um monstro banalizado.

Já o "indivíduo a ser corrigido" habita a família e suas relaçóes com demais instituiçóes. Enquanto o monstro é sempre uma exceção e remonta ao domínio da teratologia, a existência do indivíduo a ser corrigido é um fenômeno normal, ele é espontaneamente incorrigível, o que demanda a criação de tecnologias para a reeducação, uma forma de "sobrecorreção" que lhe permita a vida em sociedade. A partir da figura do "indivíduo a corrigir" é possível a germinação daquilo que, 
no final do século XIX, emergirá em meio aos domínios disciplinares como o saber sobre o crime: a criminologia.

Por fim, há a figura da "criança masturbadora", e envolve exclusivamente a família burguesa entendida como um dispositivo de poder responsável por velar contra a masturbação: "[...] o segredo universal, o segredo compartilhado por todo mundo, mas que ninguém comunica a ninguém" (Foucault, 2001, p. 74). A "criança masturbadora”, o "onanista", será a figura que acabará por encobrir as demais e deter o essencial dos problemas que giram em torno da anomalia. Virtualmente qualquer patologia mental, debilidade física ou vício moral poderia ser desencadeado devido à prática do onanismo segundo o então ideário médico burguês.

De toda forma, essas três figuras vão permanecer claramente delimitadas somente até meados do século XIX. Após o desenvolvimento da noção de degenerescência por Morel (1857), toda sorte de anormalidades é atribuída a uma "fonte orgânica difusa" que perturba constitutivamente as funçóes mentais e/ou físicas de certos indivíduos e, de modo cada vez mais grave, de seus herdeiros biológicos (Foucault, 2001). Essa teoria da degenerescência é a origem de todas as teorias eugênicas que irão desenvolver-se, especialmente as discussóes evolucionistas spencerianas que se apoiam em Darwin para identificar estigmas físicos da anormalidade como indicativos de uma criminalidade, como no caso da escola italiana de Lombroso e seus discípulos (Foucault, 2001).

Não por acaso, a medicina toma a mulher como ponto focal da intervenção do poder. Ela é a responsável pelo desenvolvimento e pela saúde de cada um dos integrantes do lar (Matos, 2003). Este formato se mantém: há um modelo hegemônico de como os sujeitos devem existir. Existências que servem para fundamentar, por meio de argumentos e da circulação de discursos, a perpetuação (e legitimação) de algumas formas de violência e do náo reconhecimento destas como tais.

Inventam-se diferentes estratégias para enfrentar um sistema perverso de produção baseado na exploração e opressão. Intencionalmente ou não, são resistências, produções de vida. Mas também são exercícios de poder, de dominação. O poder se dá na relação e, para todos estes que transgridem a norma, há efeitos sérios: processos de renormatização, de exclusão e de eliminação.

Para Baptista (1999), diversos especialistas constroem teorias, ideias e conceitos sobre determinadas categorias de sujeitos, divulgadas amplamente na mídia e exercitadas em diferentes práticas. Falas que tomam a diferença como uma carência, algo negativo, que necessita de tutela e de pena. Justifica-se, assim, a eliminação de populaçóes a partir de seus modos de existência que não se enquadram nas normas. 
O fio da faca que esquarteja, ou o tiro certeiro nos olhos, possui alguns aliados, agentes sem rostos que preparam o solo para esses sinistros atos. Sem cara ou personalidade, podem ser encontrados em discursos, textos, falas, modos de viver, modos de pensar que circulam entre famílias, jornalistas, prefeitos, artistas, padres, psicanalistas, etc. Destituídos de aparente crueldade, tais aliados amolam a faca e enfraquecem a vitima, reduzindo-a a pobre coitado, cúmplice do ato, carente de cuidado, fraco e estranho a nós, estranho a uma condição humana plenamente viva (Baptista, 1999, p. 46).

Os amoladores de facas, diz o autor, "à semelhança dos cortadores de membros, fragmentam a violência na cotidianidade, remetendo-a a particularidades, a casos individuais" (Baptista, 1999, p. 46). Onde estarão, pergunta ele, os amoladores de facas? E continua:

Já que invisíveis no dia-a-dia, a presença desses aliados é difícil de detectar. A ação desse discurso é microscópica, complacente e cuidadosa. Não seguem as regras dos torturadores, que reprimem e usam a dor. Ávidos por criarem perguntas e respondê-las, por criar problemas e solucioná-los, defendem um humanismo que preencha o vazio de um homem fraco e sem força, um homem angustiado e perplexo, necessitado de tutela (Baptista, 1999, p. 48).

$\mathrm{O}$ que têm em comum, afinal, os amoladores de facas? "Apontar o preconceito seria uma ingênua dedução, uma análise que justifica e alimenta os autoritários 'pontos de vista', os relativismos e a ênfase na boa ou má consciência” (Baptista, 1999, p. 49). Os "pontos de vista" fundam-se no que os amoladores de facas têm em comum: a presença camuflada do ato genocida. "São genocidas, porque retiram da vida o sentido de experimentação e de criação coletiva. Retiram do ato de viver o caráter pleno de luta política e da afirmação de modos singulares de existir" (Baptista, 1999, p. 49).

Por que trazer para uma discussão sobre o enfretamento à violência sexual o conceito de amoladores de facas? Porque para além da questão da criminalização está a pergunta: “onde estão essas práticas que amolam facas?”. E em que sentido a prática de amolar facas vai de encontro a práticas de direitos humanos? Quem são os amoladores de facas? E, ainda, em quais momentos amolamos facas? $\mathrm{O}$ que fazer para modificar a situação cotidiana de violência e exclusão de modos de existência? Como afirmar direitos sexuais e enfrentar a violência sexual? Com quais armas? 


\section{Com quais armas?}

Reinventar as relações sociais que dizem respeito à sexualidade não significa criar um novo sistema de governo. Mais do que isso, a potência de transformação está nas relaçóes, nas práticas e experiências dos sujeitos consigo e com os outros - na micropolítica (Guattari \& Rolnik, 1996).

Por que há critérios tão rígidos e estabelecidos sobre a forma como operamos com nossos corpos, nossos desejos, nossas relaçóes?

Para Guattari e Rolnik (1996), há um processo de produção massificada de subjetividades que compóe e sustenta o sistema capitalista. Segundo os autores: "[...] injeta-se representaçóes nas mães, nas crianças, como parte do processo de produção subjetiva. [...] Há uma espécie de reciclagem ou de formação permanente para voltar a ser mulher ou mãe" (Guattari \& Rolnik, 1996, p. 33).

Os processos de subjetivação são hegemonicamente produzidos em modelos normalizados; articulados por sistemas hierárquicos, por sistemas de valores e sistemas de submissão. Além disso, a subjetividade é internalizada como algo que precisa "ser preenchida", oposta a um modo de subjetivação singular, conceituado por Guattari e Rolnik (1996) como "processos de singularização" - a recusa de modos de manipulação preestabelecidos.

Apostamos na potência de diferenciação e criação de novos problemas e com isso novas possibilidades, através dos "estranhamentos" e breakdowns ${ }^{2}$, relacionadas a experimentaçóes do corpo e da sexualidade consideradas "anormais". É a diferença como possibilidade de construção de novos modos de existência e reinvenção das relações sociais.

Nas palavras de Bicalho (2005, p. 155), "o humano é instituído ao mesmo tempo em que institui práticas, conceitos e saberes [] O instituinte (capacidade de contestação, inovação) e o instituído (a ordem estabelecida, os valores, os procedimentos habituais de previsão)". Tais processos são engendrados constantemente e, por isso, são momentâneos.

Uma pista é trazida até nós por Deleuze e Guattari (1995), que apontam a dimensão rizomática ${ }^{3}$ das produções subjetivas. Somos todos atravessados por multiplicidades, em um processo de constante movimento. Como a grama, não há um ponto único de origem, uma entrada correta, nem mesmo um final, orientação ou destino. Foucault pensa da mesma maneira a construção da história pelos cartógrafos e arquivistas que colocam em análise os regimes de verdade (Foucault, 1979; Deleuze \& Parnet, 1988).

Quando falamos de violência e discriminação, do que tratamos? Podemos pensar em agressões físicas e brigas, bem como em situações de exclusão de sujeitos dos processos educativos e de restrição na garantia de seus direitos. 
É importante destacar que a violência não se dá por acaso; faz parte de um complexo sistema normativo que, uma vez transgredido, provoque açóes de punição, o que é chamado por Dornelles (1988) de processos de criminalização. Para o autor, as regras de uma sociedade estão materializadas em um código penal, que legisla sobre o que é crime, mas não se restringe a isto. Estas normas serão critérios para definir quem é perigoso e que práticas são inaceitáveis para o grupo social.

O dispositivo da sexualidade, articulado por relaçóes de gênero, atravessa os modos de os sujeitos se produzirem. Será que uma situação de violência é simplesmente a ação de um "monstro"? Para além de se debruçar sobre o indivíduo, podemos pensar o que há de coletivo nestas situações, que são mais que fatos isolados.

As práticas de violência e discriminação são a eliminação de "um corpo indisciplinado", que não segue as regras de gênero e as normas sexuais. Mas também a regulação de uma populaçáo pretensamente "sadia", livre daquelas práticas consideradas "indesejadas", porque estas colocariam em risco toda sociedade. Além disso, as práticas de violência produzem o comportamento dentro das normas.

Falar de violência sexual não é apenas pensar o "agressor" e a "vítima", mas como esses processos atravessam todos nós. De acordo com Batista (2003), a produção de medo e insegurança, através de discursos e práticas cotidianas, justifica e legitima políticas públicas de repressão e extermínio contra populações determinadas. $\mathrm{O}$ medo se torna um atravessamento muito potente na produção de modos de existir em que outros - não hegemônicos - são assassinados, eliminados com frieza e com a "melhor das intençôes", para proteção do indivíduo e em defesa da sociedade. Táticas naturalizadas de manutenção, tomadas como verdade.

\section{Que outros lugares podemos construir, entáo?}

Louro (2004) aponta que a visibilidade das diferenças sobre gênero e sexualidade questiona as normas estabelecidas. Como aponta Kastrup (2007), as diferenças potencializam a reinvenção do mundo, ao colocar em análise construçóes antes universalizadas. Por isso, Louro (2004) entende que podemos transformar os modelos instituídos tomando a sexualidade e o gênero como questóes. As estratégias de controle de corpos e populaçóes tomam a sexualidade como fundante da subjetividade humana, e nós somos constantemente atravessados por esse paradigma. Então, não vamos ignorá-lo como uma fantasia, mas reconhecê-lo como uma construção, que pode tomar outros caminhos. Não falamos de uma demolição exatamente e sim de uma reinvenção. 
Que outros processos de produção de subjetividade são possíveis, e como nós, profissionais, podemos potencializá-los?

Um dos caminhos possíveis é o debate coletivo sobre sexualidade e gênero, em especial situaçôes de violência. Por que alguns são escolhidos? O que afirmamos quando ficamos em silêncio? Ou seja, para além da repressão, discussão: a proibição não problematiza os processos que fundamentam estas situaçôes. Se dois profissionais têm práticas completamente divergentes e ambos encontram-se extremamente implicados, não basta eleger um "certo", mas construir o difícil caminho do híbrido e de novas possibilidades.

Assim, falar de direitos sexuais e do enfrentamento à violência sexual não é meramente o tema de uma mesa, dentro de um colóquio. Dentro da nossa organização social, das maneiras como aprendemos a existir e a nos relacionarmos, vamos cotidianamente problematizar gênero e sexualidade como diversidade que nos constitui. Deste modo, a aposta em um trabalho diz respeito a um modo de funcionamento tal qual uma caixa de ferramentas. É preciso que funcione, e não para si mesma. Que os encontros funcionem como máquinas de guerra, e que as publicações, produtos deste colóquio, funcionem como instrumentos de combate. Para continuarmos acreditando na potência da coletivização e na invenção de outras práticas que engendrem e potencializem novas subjetividades, fazendo emergir discursos e práticas diversos, mais potentes no sentido de desafiar e colocar em análise as violências contemporâneas.

\section{Referências}

Baptista, L. A. (1999). A atriz, o padre e a psicanalista - os amoladores de facas. In: Cidade dos sábios (pp. 45-49). São Paulo: Summus.

Batista, V. M. (2003). O medo na cidade do Rio de Janeiro: dois tempos de uma história. Rio de Janeiro: Revan.

Bicalho, P. P. G. (2005). Subjetividade e abordagem policial: por uma concepção de direitos humanos onde caibam mais humanos. (Tese de Doutorado. Programa de Pós-Graduação em Psicologia da Universidade Federal do Rio de Janeiro, Rio de Janeiro, RJ).

Deleuze, G. \& Parnet, C. (1988). Diálogos. São Paulo: Escuta.

Deleuze, G. \& Guattari, F. (1995). Mil platôs, v. 1. Rio de Janeiro: Editora 34.

Dornelles, J. R. (1988). O que é crime. São Paulo: Brasiliense.

Foucault, M. (1988). Historia da sexualidade I: a vontade de saber. Rio de Janeiro: Graal.

Foucault, M. (1979). Microfisica do poder. Rio de Janeiro: Graal.

Foucault, M. (2001). Os anormais. São Paulo: Martins Fontes. 
Foucault, M. (2002). Em defesa da sociedade. São Paulo: Martins Fontes.

Foucault, M. (2003). Vigiar e punir. Petrópolis: Vozes.

Fry, P. \& Macrae, E. (1993). O que é homossexualidade. São Paulo: Brasiliense.

Guattari, F. \& Rolnik, S. (1996). Micropolítica - Cartografias do desejo. Petrópolis: Vozes.

Kastrup, V. (2007). A invenção de si e do mundo: uma introdução do tempo e do coletivo no estudo da cognição. Belo Horizonte: Autêntica.

Louro, G. L. (2004). Um corpo estranho: ensaios sobre sexualidade e teoria queer. Belo Horizonte: Autêntica.

Matos, M. I. S. (2003). Delineando corpos: as representaçóes do feminino e do masculino no discurso médico. In: M. I. S. Matos \& R. Soihet (orgs.). O corpo feminino em debate (pp. 107-128). São Paulo: Editora UNESP.

Morel, B.-A. (1857). Traité des dégénérescences physiques, intelectuelles et morales de l'espèce humaine et les causes qui produisent ces variétés maladives. Paris: Baillière.

Rauter, C. (2003). Criminologia e subjetividade no Brasil. Rio de Janeiro: Revan.

Rossotti, B. G. P. \& Campos, A. T. (2010). Assegurados dos direitos: por uma cartografia do cárcere. (Monografia de Graduação. Curso de Formação de Psicólogos da Universidade Federal do Rio de Janeiro, Rio de Janeiro, RJ).

\section{Notas}

${ }^{1}$ Texto produzido para o I Colóquio Nacional sobre Direitos Sexuais da Criança e Adolescente, na Pontifícia Universidade Católica do Rio de Janeiro, junho de 2011.

${ }^{2}$ De acordo com Kastrup (2007), a invenção de novos problemas enfrenta os limites da ciência moderna na busca incessante e impossível por pureza absoluta de elementos, que na verdade sempre se produzem em composição. Segundo Bicalho (2005), os breakdowns produzidos em ato problematizam nossas açóes instituídas, lançando luz a relaçóes naturalizadas e, com isso, possibilitam a invenção de outros possíveis.

${ }^{3}$ De acordo com Deleuze e Guattari (1995), fazer o múltiplo significa retirar a centralidade de uma origem, gênese ou ponto fundante de qualquer processo produtivo. "Subtrair o único da multiplicidade a ser construída; escrever a n-1. Tal sistema poderia ser chamado de rizoma” (Deleuze \& Guattari, 1995, p. 15).

Recebido em 14 de novembro de 2011 Aceito para publicação em 28 de março de 2012 